\title{
Student Engagement and Success Using an Inquiry Approach and Integrated Curriculum in Primary Education
}

\author{
Alison Board
}

\begin{abstract}
Alison Board is a teacher with the Toronto District School Board. Her interest in the Reggio Emilia approach to education has led to opportunities for sharing her practical implementations with teachers in her school board and in other boards in Ontario. She is a contributor to the book and blog The Heart and Art of Teaching and Learning: Practical Ideas and Resources for Beginning Teachers (Elementary Teachers' Federation of Ontario, 2011).Email: alison.board@tdsb.on.ca
\end{abstract}

Intended for educators working within a prescribed curriculum, this article demonstrates how student engagement and success are achieved using an inquiry approach and integrating the curriculum. Alison outlines how she initially planned for this outcome by selecting four questions that were provided for the Toronto District School Board's Teaching and Learning Critical Pathways for Literacy. She then documents the children's responses throughout the inquiry to assess their understanding. Subquestions, rich narrative stories, and knowledge building were used to support the children's learning in a deeper context. Ultimately, the children with the most challenges in reading and writing were able to demonstrate their knowledge using a variety of assessment forms that included oral responses, visual arts, science journals, and technology.

What is hope? This was the inquiry question I presented to the grade 1 and 2 children in my classroom. I wanted a question that was broad enough to incorporate strands of the science and social studies curricula, as well as allow for many interpretations depending on context, as could be considered with art and language. The plan would follow the same timeline as Teaching and Learning Critical Pathways (TLCP) for Literacy, which is now standard across the Toronto District School Board (TDSB). My intention was to integrate science, social studies, art, and math within the same big idea as language, to allow time and space for inquiry with the intention to expand and deepen the question, "What is hope?" I also planned to assess the children's understanding, using photographs, recorded conversations, and observations, and provide opportunity to represent their understanding in a variety of forms. This intention was based on my previous years of experience as a kindergarten teacher who used inquiry to engage learners; I also wanted to follow a Reggio Emilia approach. My enthusiasm for an integrated and inquiry approach was often met with skepticism by primary teachers who felt restricted to cover a more prescribed curriculum than was outlined for kindergarten. I was motivated to teach a primary grade where I could present guiding questions to engage students (and myself) in a curriculum that could be considered in a nonlinear way. After reading Jeffrey Wilhelm's (2007) work on inquiry, I felt confident that I could surpass merely "covering the curriculum" and aim to design curriculum that would engage learners and support deeper understanding. Hence, my challenge was to combine and integrate a grade 1 and 2 curriculum provided in a flexible longrange plan and presented in the form of questions for inquiry-based learning.

Each school in the TDSB approaches the implementation of TLCPs in a unique way that benefits staff and student needs. At our school, we were to complete four TLCPs for language that span from September to June. We were provided with a list of possible questions that were developed by our literacy coach and influenced by the director of the Toronto District School Board, Dr. Chris Spence, and his vision of hope: "Imagine there is a clear focus on achieving student success and every student is engaged, has a voice, [has] access to a caring adult, and [has] the opportunity to develop to their full potential" (Toronto District School Board, n.d., para. 2).

Once I selected the four questions for the TLCPs for language, I then integrated the curriculum strands from the social studies, science, arts, and math curricula that fit best with each question, using a web graphic organizer. I then created subquestions to create a framework for inquiry-based learning and presented them with the four main questions as long-range plans for the year. The longrange plans were flexible, but provided a list of learning opportunities (curriculum expectations), possible excursion ideas, and a culminating task.

\section{The Integrated Pathway}

September was a time to create an inclusive environment as a foundation for inquiry-based learning. Students in grade 2 were surprised to see an art studio and blocks in the classroom, but they were quick to utilize the materials during extended inquiry time where the students could explore ways of representing their learning. We spent the first month building our classroom community and taking the time to share and listen to one another. To start the first integrated pathway, I simply asked the children, "What is hope?"

Ryder: You want something.

Alex: Being excited. 
Madeline: You wish something.

Leah: Worrying about other people.

By recording the children's responses, I could see that the children had similar ideas of hope as wanting or wishing, such as "I hope I get a new toy." Only Leah's comment seemed to differ in that it touched on worry or care for others. The children in my classroom needed an opportunity to consider hope in a deeper context. I looked at the subquestions I had developed in connection to the science and social studies curricula, such as, Why is hope important to our community? How is hope different for other communities around the world? How do the sun, air, and water (as energy/life source) give hope to people in our community and other communities around the world?

I looked to narrative as a form that could provide the stories and context needed to promote a deeper understanding of hope. Using various search engines, I located texts to read aloud that would provide opportunities to discuss the idea of hope in relation to our own community and communities elsewhere in the world.

The following four texts, which were chosen in response to the children's needs for understanding and were not in my original long-range plan, became the foundation for our inquiry:

- Lila and the Secret of Rain, by David Conway and Jude Daly

- Listen to the Wind, by Greg Mortenson and Susan Roth

- Poor Fish, by Heide Helene Beisert

- The Whispering Cloth: A Refugee's Story, by Pegi Shea and Anita Riggio

We read the books two or three times each over a period of a month. The grade 1 students easily compared their own community with the environmental issues in Poor Fish, and with teacher direction, the grade 2 students compared the people, houses, transportation, and geography presented in the other books about Pakistan, Africa, and Thailand. To support the learning needed for these comparisons, each student was provided with a field journal. We used these journals on a weekly outing to our school grounds, where we made observations about the sun, the air, or water in relation to our familiar surroundings. We would return to class and share our findings, building on our own understandings in a process Chiarotto (2011) calls knowledge building.

In my long-range plans, I had outlined the culminating task as a fabric picture, using a variety of textiles to represent the children's understanding of hope in the context of their local community (grade 1) or another community in the world (grade 2). Part of our learning included a class trip to the Textile Museum of Canada. This trip provided us with new information about the symbolism and purpose of clothing in African cultures. It also gave the students an opportunity to explore textiles, wool, and weaving in a hands-on area.

Upon returning to school from our class trip, Kieran, a grade 2 student, handed me a piece of fabric that he had just cut out, saying, "Here, Ms. Board, this is for you."

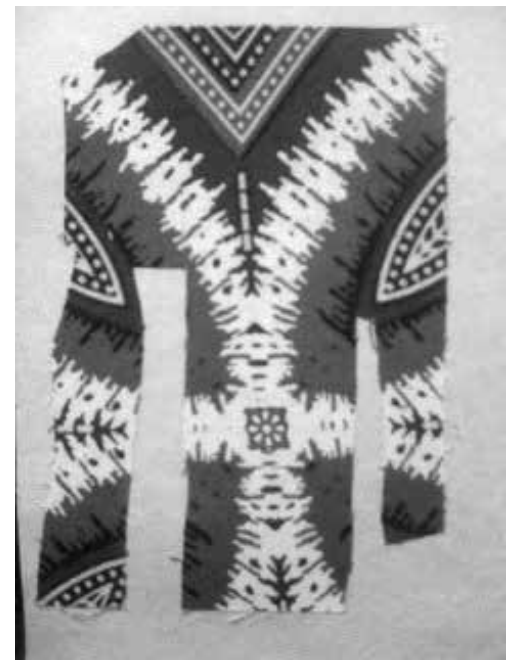

Figure 1. Student representation of African clothing, using scissors and fabric.
Kieran's representation was not petitioned or expected. I felt the need to have something written to support his representation of a garment, so I asked him to explain what it represented in words. He said, "Hunter clothes. The red symbol is good luck. They go hunting so they can eat." His written piece did not convey his understanding of symmetry as demonstrated in how he cut the garment, nor his initiative and interest which, until this time, had not been evident.

After our trip to the textile museum, extended "inquiry time" in the class to pursue topics and interests at various centres, and discussions around our four foundation books, the children started to make their own observations and connections. Integrating the science curriculum for both grades, which included focus on the sun's energy (grade 1 ) and the need for air and water (grade 2), contributed to their understanding of the texts. I asked the children again, "What is hope?"

Madeline: To keep the environment clean.

Leah: To build a school.

Alex: For rain to cool down the land, fill the wells so people will not die.

Molly: To live in a new country; to have a home.

Kieran: To go to school.

The children's responses were now reflecting their understanding of hope in other contexts. They were continuously making connections between the books that we read. They were also showing interest in locating the various countries that are the settings for the texts. When we were in the computer lab, many of the children searched their country of interest on Google Earth. Leah and Madeline were surprised to see the snow-covered mountainous terrain of Korphe, Pakistan. 


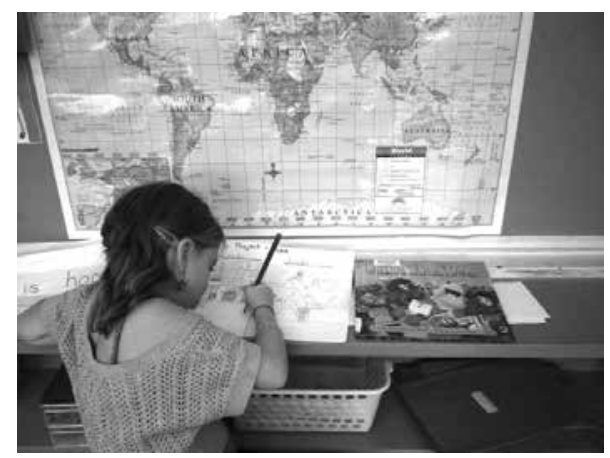

Figure 2. Leah takes her chair to work by the map where she is working on locating Korphe, Pakistan, and describing its climate.

\section{An Emergent Interest in Weaving}

An interest in weaving emerged from the children's learning regarding the importance and cultural significance of cloth in our community and communities in Pakistan, Thailand, and Africa. This interest was the result of our trip to the textiles museum, the rich texts combining themes of hope, cloth, and community, and the social studies and arts curricula.

A basic loom was set up as a centre in the classroom, on a table with chairs set on either side as an invitation for two. A basket was provided with strips of blue fabric and a limited selection of beige and grey yarn. All the children wanted to try weaving; however, over an extended time I observed three main outcomes that resulted from the weaving centre.

First, I was surprised by the unlikely partnerships that it brought together and the collaboration it encouraged. Ryder said, "We can do this together. First I hold the strings and Kate pushes the fabric through, then she holds the strings and I do it!"

Second, the loom attracted interest from some students who were not usually interested in the arts. For example, Ryan worked alone at the loom and methodically wove the materials, noting the pattern as he worked. For many of the grade 1 boys, weaving provided necessary opportunities for small motor development.

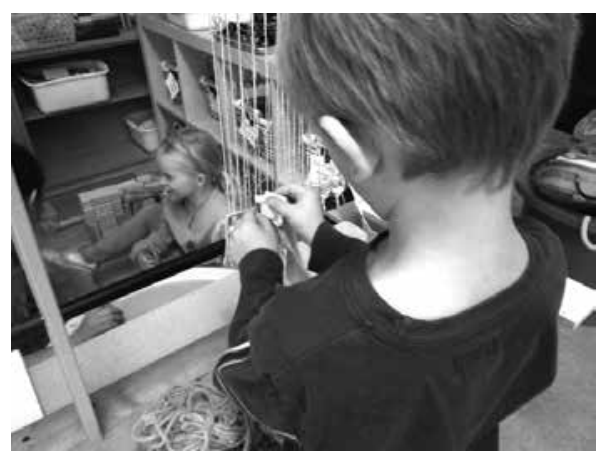

Figure 3. Ryan at the loom.

Third, the loom provided a centre for oral language development. Eve-Marie, an English language learner, was often reticent about participating in any group activities at the beginning of the year. Yet, she felt comfortable participating with others at the loom, and it was here that she engaged in dialogue while sharing in the act of weaving.

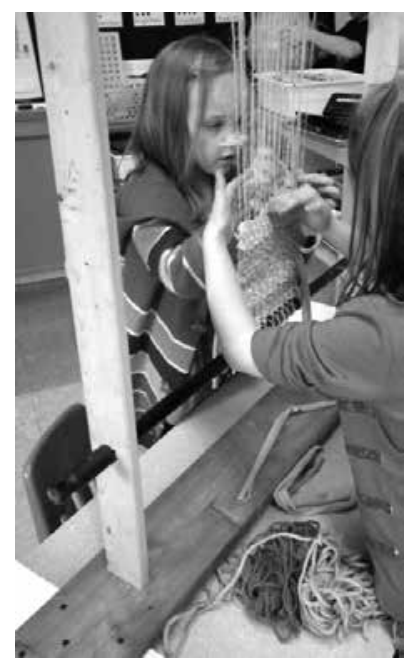

Figure 4. Eve-Marie, grade 1 English language learner, at the loom.

\section{The Culminating Project}

When it came time for the culminating project, I doubted my decision to rely on the fabric representation for assessment. So, I created a graphic organizer or template for the children to complete first. However, I found the fabric representations captured a depth of understanding that was not evident in the written task.

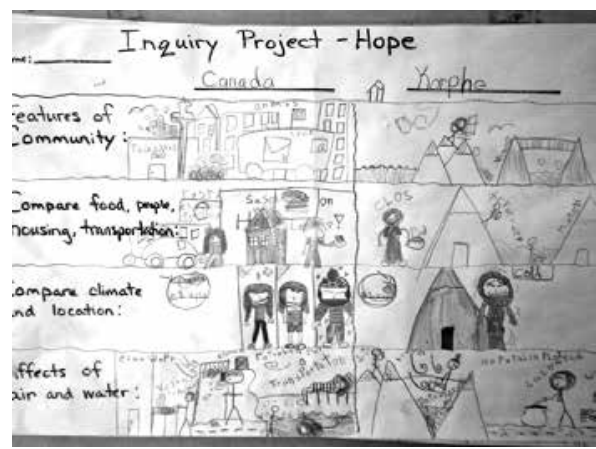

Figure 5. Graphic organizer for culminating fabric picture.

In Figure 5, grade 2 student Leah is receiving support for below-grade reading and writing skills. However, her detailed drawings represent her knowledge when comparing her community with a community in Pakistan. Note the curly lines in the mountains representing the effects of the air as wind in the higher altitude of Korphe.

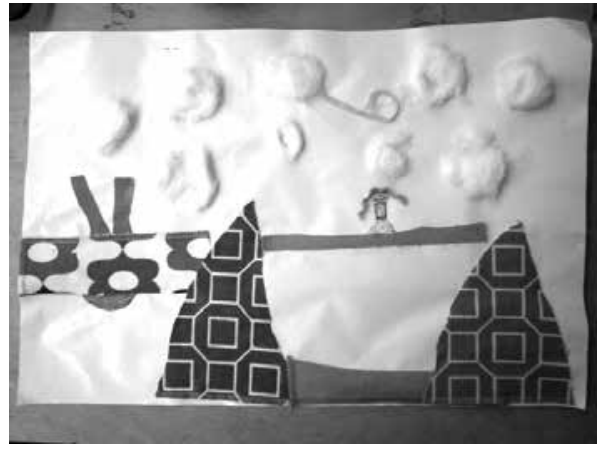

Figure 6. Culminating fabric picture, Korphe, Pakistan.

Leah's fabric representation shows the altitude of the Korphe community, the challenge of the water that was previously crossed using a wire pulley and a box to sit in, and the wise man who slipped. In Korphe, the people's need for a bridge is more clear than their need for a school. 


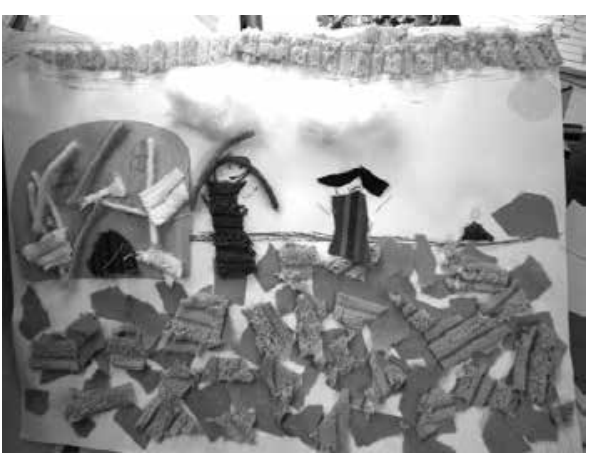

Figure 7. Culminating fabric picture, Africa.

In Figure 7, grade 2 student Molly uses fabric to effectively demonstrate her understanding of the dry African landscape. She has also shown perspective with a home and person in the background on the horizontal line, skills that were explored during instruction of the visual arts curriculum. This work demonstrates how a student can represent his or her knowledge using visual art. As Lorraine Chiarotto (2011) notes, "the fact that a student may not possess particularly strong writing skills does not mean that he or she is devoid of ideas or knowledge" (p. 24).

\section{Conclusion}

At the end of the inquiry, I asked the students if their ideas about hope had changed.

Kieran: Hope is more about needing something, like a place to live, food, or water to survive.

Leah: We pretty much have everything we need.

It was evident from these responses that the children had gained a deeper understanding of the question through their own inquiry, which had been supported using an integrated curricular approach. More importantly, the children were successful in demonstrating their knowledge and understanding in science and social studies that would not have been achievable if only paper and pencil tasks were provided. Visual art provides a valuable means of assessment. Through the documentation process, I was able to clarify my own objectives and make the children's learning visible.

\section{How To Implement an Integrated Inquiry Approach}

To implement a similar approach, brainstorm ways to connect the children to the curriculum using real-world problems or questions. Provide many, many ways to approach the inquiry, and allow for extended time periods where the children can explore their topics of interest at the computer, in an art studio, or using building materials. More specifically:

1. Make flexible plans

2. Build classroom community

3. Learn with the children

4. Share ideas as a group

5. Provide the resources and the time

5. Allow students to express understanding in many forms

6. Document and reflect

\section{References}

\footnotetext{
Chiarotto, L. (2011). Natural curiosity: Building children's understanding of the world through environmental inquiry: A resource for teachers. Toronto, ON: Ontario Institute for Studies in Education.

Elementary Teachers' Federation of Ontario. (2011). The heart and art of teaching and learning: Practical ideas and resources for beginning teachers. Toronto, $\mathrm{ON}$ : Author.

Toronto District School Board. (n.d.). Better schools today means a brighter future for children of tomorrow. Retrieved from: http://www.tdsb.on.ca/

Wilhelm, J. D. (2007). Engaging readers and writers with inquiry. New York, NY: Scholastic.
} 